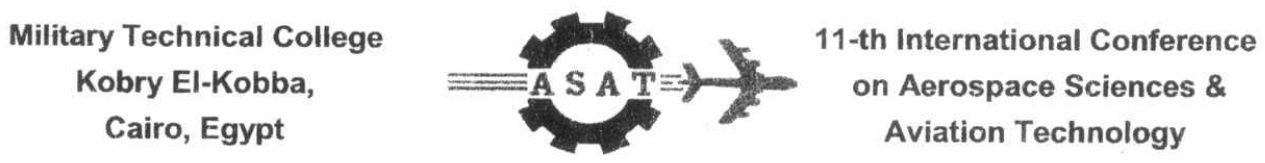

\title{
A laboratory Realization of Control Systems of Capacitor Self-Excited Induction Generator
}
F. A. Khalifa*
A. Eliwa*
W. Sabry*
M. E. A. Rahman*

\section{Abstract}

This paper presents a laboratory set-up simulation of the wind energy power system including capacitor self-excited induction generator (CSEIG). An implementation of PI, PID and Fuzzy Logic (FLC) Controllers is developed. The hardware components and circuits are also designed and realized. The influence of these control techniques on the performance characteristics of the system under consideration is examined. The obtained experimental results show that the transient response and damping performance with FLC is better than that of PI and PID controllers.

\section{Keywords:}

Wind energy, CSEIG, PI controller, PID controller and FLC 


\section{INTRODUCTION}

With the continuing increase in energy demand and fuel costs as well as possibility of depletion of fuel reserves have made it necessary to investigate and develop alternative energy sources. Of these wind energy seems to be a promising alternative to oil mainly because it does not cause environmental contamination, non-depletable and at most sites its seasonal availability shows a good correlation with the seasonal demand for energy. Wind power provides two basic types of needs:

(a) For remote applications, where an electricity grid (supply) is not available and there is a need for mechanical power such as water pumping, wind can function quite well.

(b) In other areas, where electricity grids are available, wind power can serve as an alternative to conventional forms of the power generation.

The installation of wind turbines in power systems has been developed rapidly through the last 20 years. The national and international growth rates and policies indicated that this development would continue. Various schemes for generating electricity from the wind have been proposed. These schemes can be broadly classified under the following three categories $[1,2]$ :

1) Variable speed constant frequency system (VSCF).

2) Constant speed constant frequency system (CSCF).

3) Variable speed variable frequency system (VSVF).

This paper discusses the laboratory realization and construction details of the power system under consideration, also, proposed control system is presented. The designed construction of the hardware components of the measuring and control circuit is described. The set up of the system under study is shown in Figure (1).

\section{WIND ENERGY IN EGYPT}

The government of Egypt has established the New and Renewable Energy Authority (NREA) to be responsible for the study and execution the national program for the use of wind energy. The NREA is promoting progressively the development of wind energy and has started the construction of a wind farm with a total of $600 \mathrm{MW}$ in two stages each of $300 \mathrm{MW}$ at Zaffarana, Suez gulf to be ready for operation by year 2005. One of the problems that wind energy will create in such exist in electrical power system, is the dependence of the injected power on the wind speed which can not be predicted, but the probability of a particular wind speed occurring can be estimated [3].

Time series of wind speeds and directions were collected over ten minutes intervals for the period of four years (1995-1998) at a meteorological tower. The wind direction was divided into twelve $30^{\circ}$ sectors and the weighted average wind speed $(\mathrm{m} / \mathrm{s})$ was calcu- 
lated on hourly basis. The wind variation for a typical site is usually described using the so-called Weibull Distribution, to measure wind speeds throughout a year as shown in Figure (2). The speed is between 6 and $12 \mathrm{~m} / \mathrm{s}$ during the year.

\section{Practical implementation of the control system}

The original practical system consists of the following components as shown in figure (3):

\section{Induction Generator}

The three-phase induction generator is the main component in the system. The generator is driven by a variable speed DC motor.

\section{Transducer}

The measuring unit is used to monitor the state variables of the controlled process. In this work one feedback signal is used (the terminal voltage $V_{t}$ of the IG). The terminal voltage measuring circuit delivers a dc voltage proportional to the R.M.S. value of the generator voltage. The circuit diagram of the voltage transducer is shown in Figure (4).

\section{Three Phase Control Unit}

This Block diagram consists of:

1) Fixed DC Power Supply

2) Three Phase Control Circuit

\section{Fixed DC Power Supply}

The LM7815 and LM7819 positive and negative regulators are connected as shown in Figure (5) to obtain a dual power supply for supplying the circuits $( \pm 15 \mathrm{~V})$ [4]. The output voltage of this transformer is rectified by a full wave rectifier via D1, D2, D3, D4, $\mathrm{C} 1$ and $\mathrm{C} 2$. The capacitors $\mathrm{C} 3, \mathrm{C} 4, \mathrm{C} 5$ and $\mathrm{C} 6$ are used to improve transient stability response of the power supply.

\section{Three-Phase Control Circuit}

The one line circuit diagram of the three-phase control circuit is shown in Figure (6). It is used to determine the firing instant that issues the firing pulses to the triac of the thyristor-controlled reactor. It is supplied by a dual power supply ( $\pm 15 \mathrm{~V} \mathrm{dc}$ ). The main element of this circuit is the UAA 146, which is monolithic integrated circuit. It contains:

(a) Synchronization stage, which delivers a pulse for positive ac half wave supply and a pulse for negative ac half wave supply.

(b) Memory.

(c) Monostable multivibrator.

(d) Comparator.

This integrated circuit is suitable for phase controi in high precision regulators. The output of the control circuit is composed of two separate pulses synchronized with the 
ac supply voltage (the terminal voltage of the IG), one for positive ac half wave supply at pin 10 , and the other for negative ac half wave supply at pin 14.

The two pulses are collected by the two diodes (D1 and D2) to fire the triac of the thyristor-controlled rectifier (TCR). The phase angle can be varied from 0 to $180^{\circ}$. The pulse transformer (PT) is used to isolate the output pulses from the control circuit.

\section{6- Computer Control System}

The most feasible way of implementing a digital controller is through the use of a digital computer. In recent years the developments made in the field of microcomputers have made the applications of this type of controller very attractive for control applications. Digital computers have made it possible to apply new control strategies to physical systems.

Voltage and reactive power control, which is the theme of this section, has grown in importance for a number of reasons which are summerised as follows, first, the requirement for more efficient operation of power systems has increased with the increase of fuel price. Second, the requirement for high quality of supply has increased due to the huge demand of the electronic equipment. Voltage and reactive power control is an essential tool in maintaining the quality of supply, especially in preventing voltage disturbance, which is the commonest type of disturbances.

\section{CONTROLLABLE STATIC VAR GENERATORS}

These systems are conceptually simple. They usually comprise shunt capacitors and inductors in conjunction with thyristor on/off or phase controlled switches. Their commercial success is due to their acceptable cost, coupled with desirable technical features, such as extremely fast response time, flexibility of control and continuous operation with virtually no maintenance. One basic types is presently used (although others are available) to provide variable susceptance. It is the leading VAR controlled by a fixed capacitor - thyristor controlled reactor.

Fixed capacitor - thyristor controlled reactor (FC-TCR) VAR

The basic system consists of a fixed capacitor in parallel with a thyristor controlled inductor as shown in Figure (7. a). With this arrangement a variable reactance (i.e., purely capacitive or inductive impedance) can be realized by controlling the current flow in the inductor and thereby varying its effective impedance. This is achieved by delaying the closure of the thyristor switch by an angle in each half cycle with respect to the peak of the applied voltage to control the current conduction interval. The control process is illustrated in Figure (7. b).

The thyristor-controlled reactor (TCR) 
The controlling element is the thyristor controller, shown here in Figure (8) as two oppositely poled thyristors which conduct on alternate half-cycles of the supply frequency.

\section{TUNING OF PID/FUZZY CONTROLLERS}

\section{PID controller}

The parameters of the PID controller $\mathrm{Kp}, \mathrm{Ti}$ and $\mathrm{Td}$ are manipulated to produce various response curves of a given process. Finding optimum adjustment of a controller gains for a given process is not trivial.

Figure (9) shows a Simulink model for the PID controller using Matlab PID toolbox. In this model, there are two analog input signals; the first is the generator output voltage, which comes from a measurement circuit through an A/D converter. The signal is filtered then compared with the reference voltage, result an error signal. The second is the prime mover speed, which is measured through a tachogenerator and A/D converter. The speed signal is filtered then sends to a workspace to be used to notify the speed performance during changing the generator output voltage. The output voltage error signal is processed in a discrete PID controller to get a control signal, which conditioned through a saturation block and a D/A converter. Then the output analog control voltage is used to drive the (FC-TCR) VAR circuit.

\section{Fuzzy control}

Tuning the Fuzzy controllers is a difficult task as it has many parameters to be tuned as follows:

a) Rule tuning: Changes of rules may affect the performance. However, it is not so easy to tune the rule base.

b) Membership function (MF) tuning: Changes of 'MF's may not affect the performance very much [5]. It is also not very convenient to tune MF's.

c) Gain tuning: Changes of gain affect the performance greatly. As it is easier to tune the gain than the rule base and MF's. So, the gain tuning is the most common way for tuning Fuzzy controllers.

A Simulink model for the Fuzzy controller using Matlab Fuzzy toolbox is shown in Figure (10).

\section{EXPERIMENTAL RESULTS}

The experimental results of the power system under study are investigated when the system is equipped with three proposed controllers. These are:
a) PI controller,
b) PID controller, and 
c) Fuzzy logic controller.

For each control system, the following cases of studies are considered:

a) $75 \%$ loading (3/4 load) condition.

b) $100 \%$ loading (full load) condition.

c) Step increase in reference voltage by $5 \%$.

d) Step decrease in reference voltage by $10 \%$.

In the first two case studies, the proposed controllers are introduced when the system is In the first two case studies, the proposed controllers are inter 20 seconds with the pradetening value according to each case study and it's sustained for 20 seconds, then it will be removed. In the last two case studies, the system responses with the proposed controllers are investigated when the system is subjected to step increase in the reference voltage by $5 \%$ and step decrease in the reference voltage by $10 \%$ after 25 second from the simulation starting time.

Results for $75 \%$ and $100 \%$ loading increase

The response of induction generator as represented by its terminal voltage following the application of $75 \%$ and $100 \%$ load is shown in Figures (11), (12).

In these Figures, a comparison between the IG performance as presented by its terminal voltage / time response is demonstrated when equipped with Fuzzy logic, PI and PID controllers. In This case study the machine is assumed to load as the previous cases. It can be seen from this figure that the transient performance of the system when equipped with the different control strategies mentioned above is acceptable. However a better transient response and damping characteristic is obtained with Fuzzy logic controller. The tuning difficulties associated with PID controllers to the variations of the system operating conditions, makes the application of fuzzy logic controller is preferable.

\section{CONCLUSIONS}

An implementation study of the performance characteristics of the induction generator when equipped with static VAR compensator (SVC) is demonstrated. A design and realization of this static VAR compensator is also presented. It consists of three-phase thyristor controlled reactors and three phase fixed capacitor. The thyristor-controlled reactors are connected in delta to remove the $3^{\text {rd }}$ harmonics from the line currents. The three phase capacitors are connected in star. The control circuit is also designed and realized. The output of this control circuit in each supply cycle is composed of two separate pulses synchronized with the terminal voltage of the induction generator, one for the positive ac supply half wave and the other for the negative supply half wave. The two output pulses are balanced so that the even harmonics are removed from the thyristor controlled reactors 


\section{REFERENCES}

[1] James F. Manwell and Duane E. Cramack, "Understanding wind energy", http://www.vita.org, Volunteers in technical assistance, Technical part 11, pp. 1-20, January 1990.

[2] Hani Khaled, "Computer control of wind driven induction generator system", Ph.D. thesis, MTC, Cairo, 1990.

[3] Mohamed El-Sayed, Mohamed Salah El-Sobki and Effat Moussa, "Wind energy impact on the reliability of Egyptian generation system", The 8th international Middle East power system conference (Mepcon 2001), pp, 975-981, University of Helwan, Cairo, Egypt, December 29-31, 2001.

[4] Abd-El-Fatah El-Sayed Elewa, "Influence of static VAR compensator on power system dynamics", Master thesis, MTC, Cairo, 1994.

[5] R. Mostafa, A. El-Kosy and U. Abo-Zayed, "Simulation of Fuzzy controlled disc type DC motor fed from quasi resonant converter using simulink", 9th inter. Conference on computer theory and applications, ICCTA 99, pp. 15-23, Alex., Egypt, August 1999.

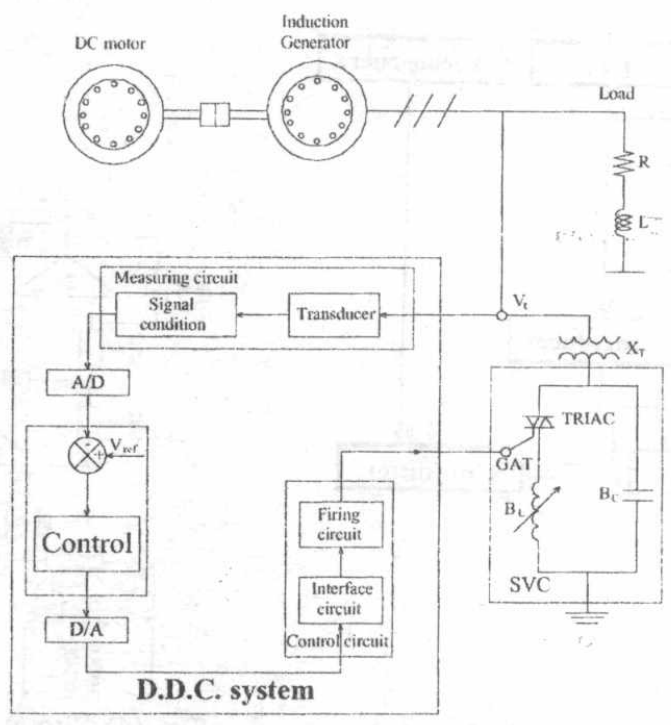

Fig.(1) System under implementation study. 


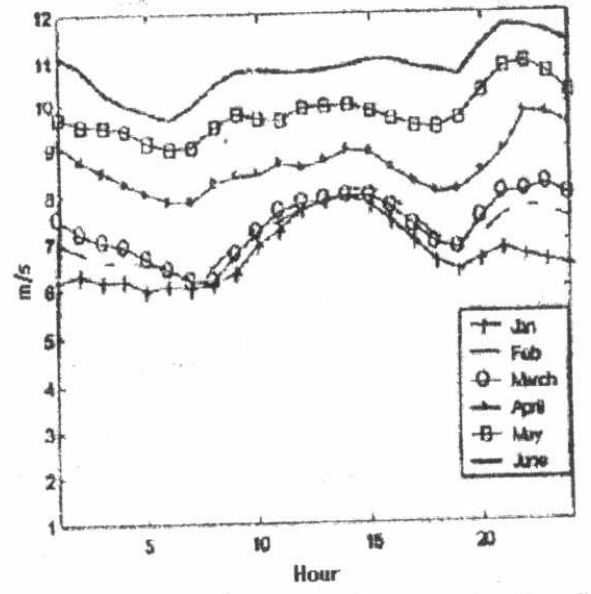

Fig. (2. a) Average wind speed for the first six months of the year.

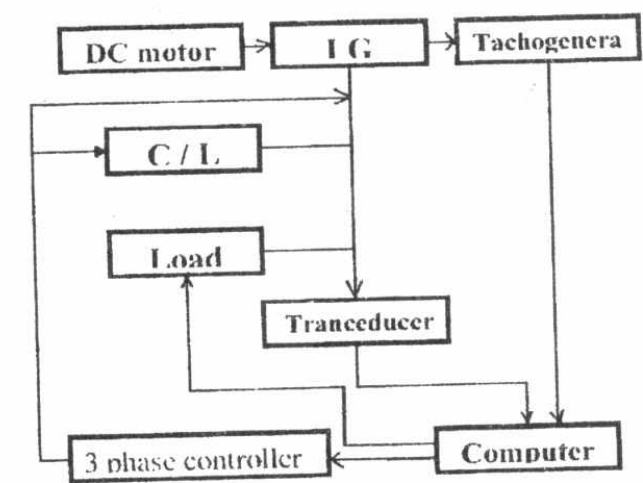

Fig. (3) The original practical system.

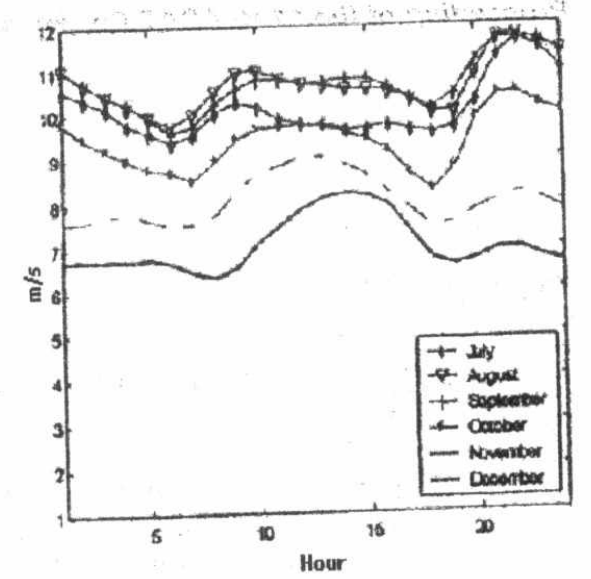

Fig. (2. b) Average wind speed for the second six months of the year.

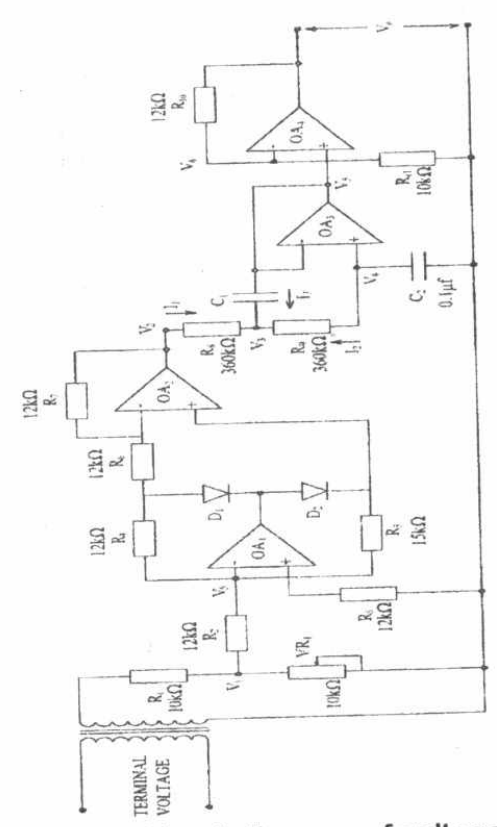

Fig. (4) Circuit diagram of voltage transducer. 


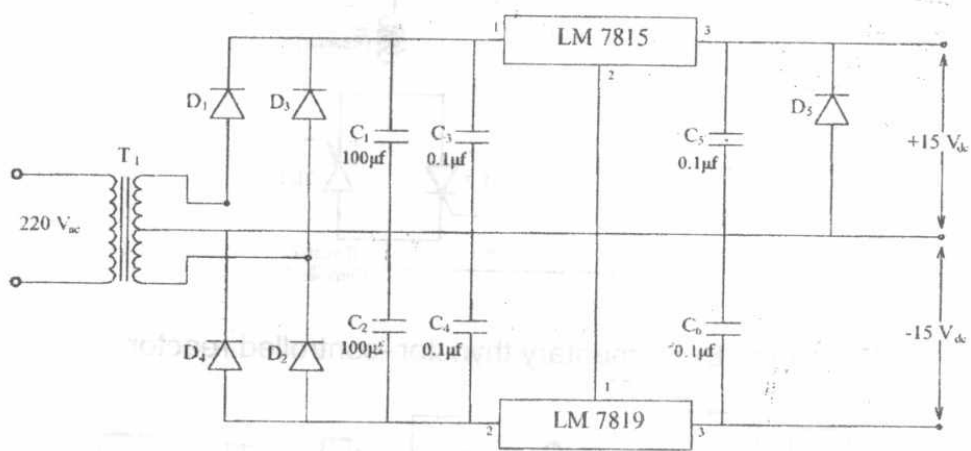

Fig. (5) Fixed dc power supply.

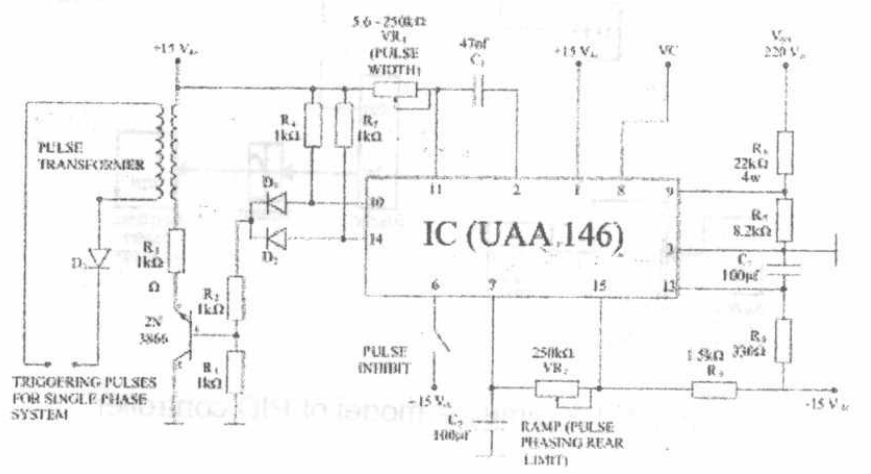

Fig. (6) One Line Control Circuit Diagarm

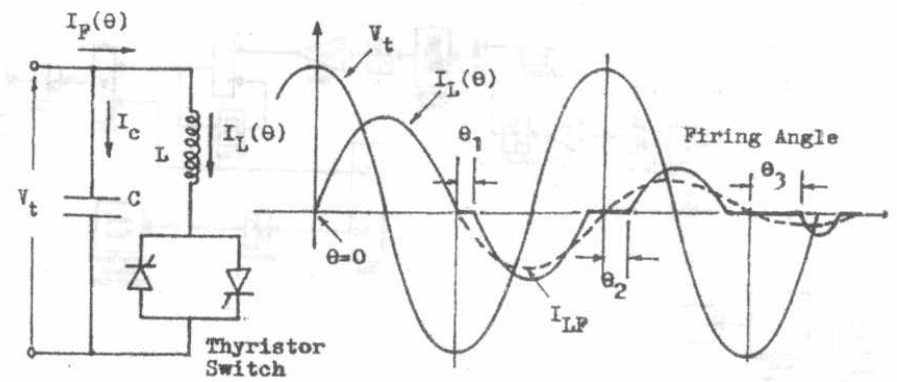

(a)

(b)

Fig. (7) Thyristor controlled reactor, a) Circuit diagram, b) Current and voltage waveform. 


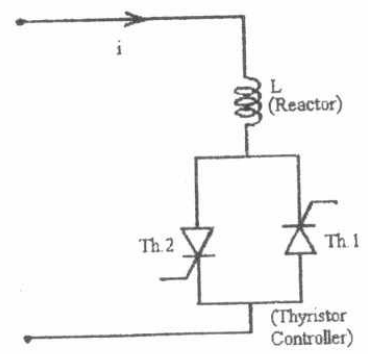

Fig. (8) Elementary thyristor-controlled reactor.

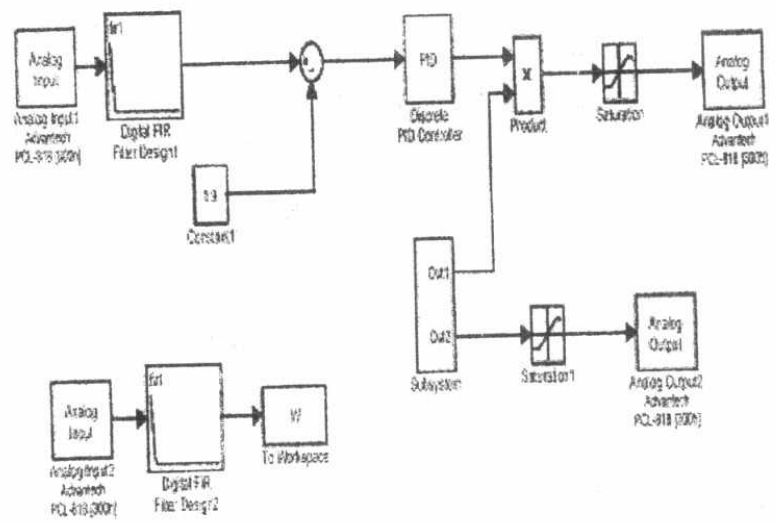

Fig. (9) A Simulink model of PID controller.

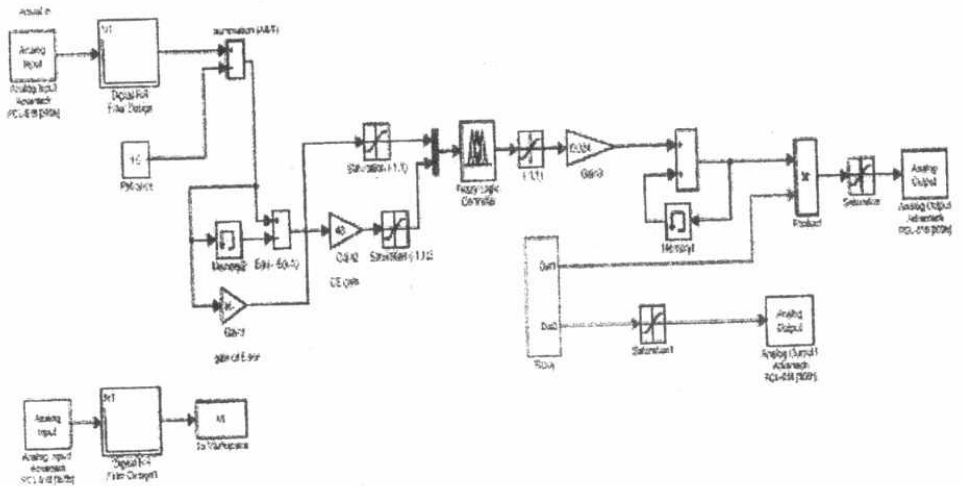

Fig. (10) A simulink model of Fuzzy controller. 


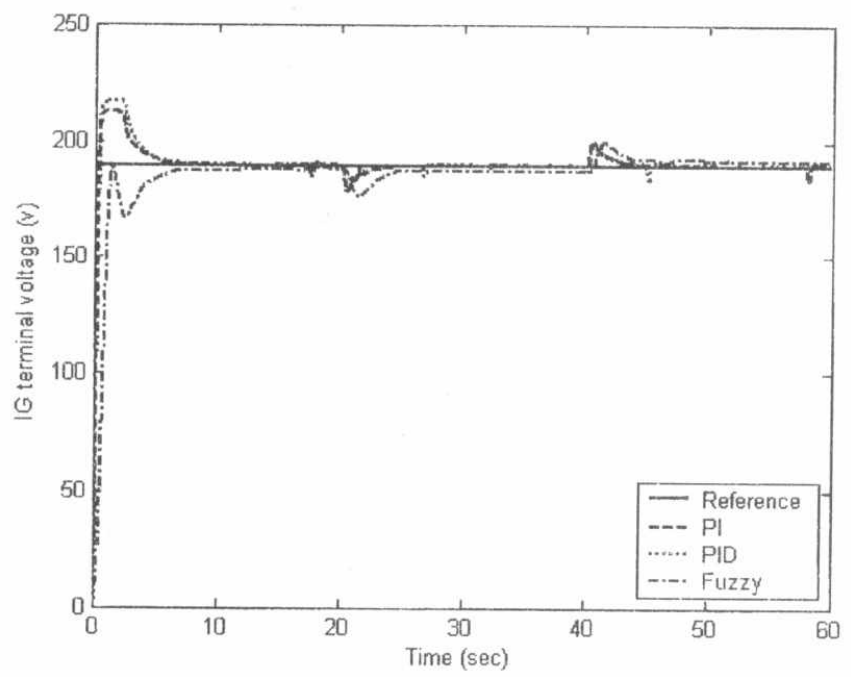

Fig. (11) Terminal voltage / time response with PI, PID \& Fuzzy logic controller at $75 \%$ loading conditions.

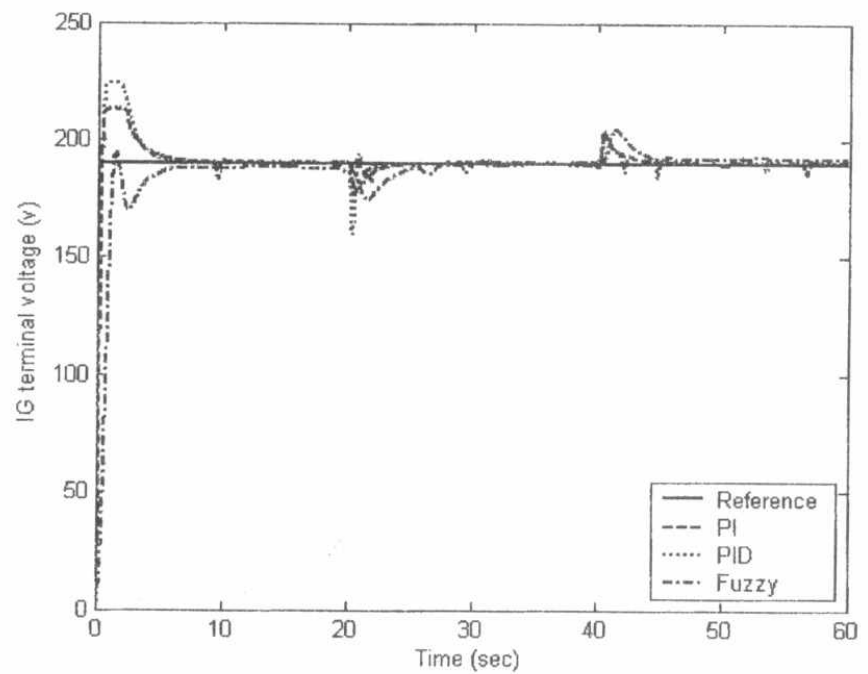

Fig. (12) Terminal voltage / time response with PI, PID \& Fuzzy logic controller at $100 \%$ loading conditions. 